\title{
The paleo-climate condition controls sedimentary As burial in Datong Basin
}

\author{
WENJING LIU, XIANJUN XIE AND YANXIN WANG
}

China University of Geosciences (Wuhan)

Presenting Author: Joius_1@cug.edu.cn

Sedimentary arsenic (As) burial in the early diagenesis is closely related to paleo-climate, which influences the intensity of weathering and the deposition of Fe/Al oxides. To illustrate the effects of paleo-climatic changes on As burial, the study investigated the geochemical parameters, organic matter (OM) characterization, dating analysis, and As species of sediment samples at depths from 0 to $50 \mathrm{~m}$. OSL dating analysis showed the highest As concentrations corresponded to the relatively warm and humid climate, and the lowest concentrations were associated with the cold and dry climate. Grain size distribution results indicated $\mathrm{Al}, \mathrm{Fe}$, and $\mathrm{OM}$ were associated with finegrained fractions. Sedimentary As contents were significantly and positively correlated with $\mathrm{Fe}_{2} \mathrm{O}_{3}, \mathrm{Al}_{2} \mathrm{O}_{3}$, and $\mathrm{OM}$ content ${ }^{[1]}$, suggesting the burial of fine-grained fractions during warmhumid climate is beneficial to As deposition in Datong Basin, and this was further supported by the sequential extraction result that the majority of As was bound to Fe hydroxides-bound and OM-bound fractions. In addition, fluorescence features indicated the sedimentary $\mathrm{OM}$ was terrestrial. And the positive relationships between As and $\mathrm{Sr}$, Ti were explained that strong chemical weathering is a key process controlling As burial. In summary, the increased burial of OM and fine-grained fractions enriched in $\mathrm{Fe}$ and $\mathrm{Al}$ oxides due to enhanced chemical weathering under the warm-humid conditions favors As burial in Datong Basin.

[1] Liu et al. (2020), Environmental Pollution 262, 114305. 